\title{
Cases of Salmonella Urbana in Finland, the Czech Republic and Latvia, January-February 2010
}

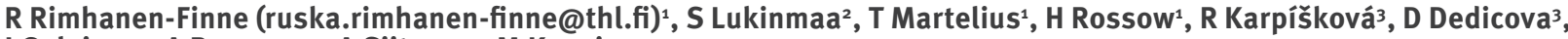

J Galajeva ${ }^{4}$, A Bormane ${ }^{4}$, A Siitonen ${ }^{2}$, M Kuusi $^{1}$

1. National Institute for Health and Welfare, Epidemiologic Surveillance and Response Unit, Helsinki, Finland

2. National Institute for Health and Welfare, Bacteriology Unit, Helsinki, Finland

3. National Institute of Public Health, Prague, Czech Republic

4. State Agency “Infectology Center of Latvia”, Riga, Latvia

Citation style for this article:

Citation style for this article: Rimhanen-Finne R, Lukinmaa S, Martelius T, Rossow H, Karpíšková R, Dedicova D, Galajeva J, Bormane A, Siitonen A, Kuusi M.

Cases of Salmonella Urbana in Finland, the Czech Republic and Latvia, January-February 2010. Euro Surveill. 2010;15(11):pii=19511. Available online: http://www. eurosurveillance.org/ViewArticle.aspx?Articleld=19511

This article has been published on 18 March 2010

A cluster of 14 cases of Salmonella Urbana cases in Finland, the Czech Republic and Latvia were identified in January-February, 2010. The majority of cases (11) were male and children under 16 years of age. The investigation is currently ongoing and comparison of pulsed-field gel electrophoresis (PFGE) profiles of the isolates suggests that the cases may have a common source of infection.

On 5 February, the Finnish National Salmonella Centre (NSC) in the Bacteriology Unit of the Finnish National Institute for Health and Welfare (THL) reported four laboratory confirmed cases of $S$. Urbana (30:b:enx) to the THL Unit of Epidemiologic Surveillance and Response. Isolates originated from different parts of the country. The samples were taken between 13 and 30 January. According to the patients' physicians, none of them had been travelling abroad prior to the onset of illness with symptoms of diarrhoea and fever. Three of the cases were children under four years. A link between the cases was suspected because of temporal association of isolates of a very unusual Salmonella serotype. During the last 30 years, only three human cases of domestically acquired $S$. Urbana were reported in Finland. According to the Finnish Food Safety Authority, S. Urbana was found once in peanuts (in 2003) and in dog treats (in 2008). [H. Kuronen; personal communication].

In order to build a hypothesis of the source of the infection, cases or their guardians were interviewed using an extensive questionnaire focussing especially on food items generally consumed by children and to animal contacts, or contacts to animal feed. To map the occurrence of $S$. Urbana infection in other European countries, an inquiry to detect potentially linked cases in other countries was conducted through the Programme on Food- and Waterborne Diseases and Zoonoses network [5].

TABLE

Clinical characteristics of S. Urbana cases, Finland, Latvia and the Czech Republic, 2010

\begin{tabular}{|c|c|c|c|c|c|}
\hline Country & Age & Gender & Clinical picture & Sample & Hospital care \\
\hline Finland & 11 months & $\mathrm{F}$ & bloody diarrhoea & faecal & yes \\
\hline Finland & 1 year & $\mathrm{F}$ & bloody diarrhoea & faecal & yes \\
\hline Finland & 3,5 years & M & diarrhoea & faecal & no \\
\hline Finland & 2 years & M & bacterial arthritis, no gastrointestinal symptoms & faecal+synovial fluid & yes \\
\hline Finland & 13 years & M & diarrhoea & faecal & no \\
\hline Finland & 35 year & M & diarrhoea & faecal & yes \\
\hline Latvia & 2 years & M & diarrhoea & faecal & \\
\hline Czech Republic & 7 years & M & watery diarrhoea & faecal & yes \\
\hline Czech Republic & 4 years & M & diarrhoea & faecal & no \\
\hline Czech Republic & 6 years & M & vomiting* & faecal & yes \\
\hline Czech Republic & 1,3 years & M & diarrhoea & faecal & yes \\
\hline Czech Republic & 2,5 years & M & diarrhoea & faecal & yes \\
\hline
\end{tabular}

*Vomiting since November 2009, no diarrhoea/abdominal pain, hospitalised 18.1.2010 


\section{Investigations to date}

A case was defined as a person with S. Urbana (30:b:enx, PFGE profile SURBXB.0002 and SURBXB.0003) infection in the European Union (EU) with the date of sampling between 1 January and 14 February 2010. In total 14 cases met the case definition (Table 1 ).

Twelve of the cases were children under 16 years. The median age was five years (age range 11 months old to 35 years old). Eleven were males. Three cases had a bacterial invasive disease, Salmonella isolated from blood or synovial fluid. Ten cases were hospitalised. Seven cases were from different parts of Finland, six from different parts of the Czech Republic and one from Latvia. In Finland, the descriptive epidemiological study suggested that all cases could have been exposed to dogs and all children had eaten raisins. In the Czech Republic, the epidemiological investigation revealed contact with dogs only in two cases and consumption of raisins in one case. No potential common source was detected in the Czech cases. The Latvian case had had no contact with dogs and had not consumed raisins, but the family had a cat whose feed was sampled and tested with negative results. The dog faeces, dog treats and raisins collected from the homes of the Finnish cases tested negative for salmonella.

PFGE profiles from the three countries, Finland, the Czech Republic and Latvia, were indistinguishable

\section{FIGURE 1}

PFGE profiles of $S$. Urbana isolates from Finland, Czech Republic and Latvia when digested with XbaI enzyme.
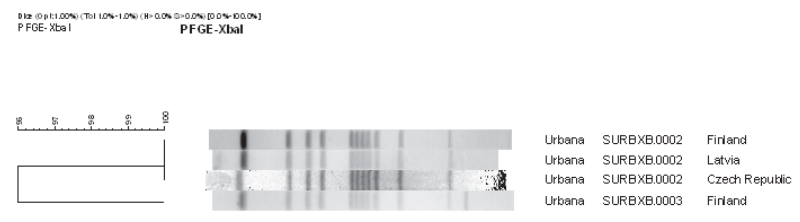

PFGE; Pulsed-field gel electrophoresis

\section{FIGURE 2}

Cases of $S$. Urbana by date of onset of gastrointestinal symptoms and country, 12 January-7 February 2010

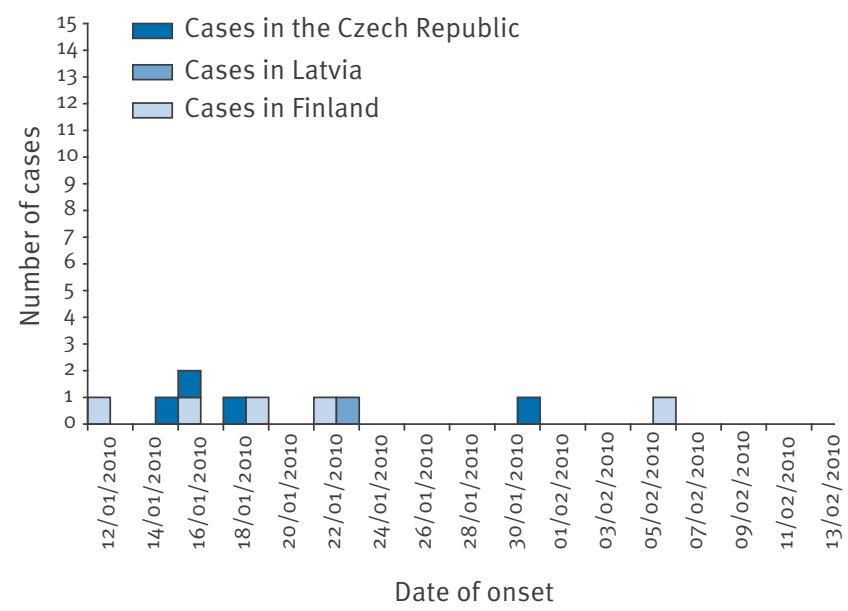

when compared to each other (Figure 1) indicating that the infections might have had a common source.

One Finnish PFGE profile (SURBXB.0003) had an extra band. This minor difference might be caused by a plasmid which salmonellae can spontaneously lose or acquire. It is also possible that a recent point mutation, deletion or insertion in the DNA had occurred. $S$. Urbana strains were sensitive to all antimicrobial agents tested (ampicillin, chloramphenicol, cefotaxime, imipenem, mecillinam, nalidixic acid, neomycin, sulfonamide, tetracycline, trimethoprim, streptomycin, and ciprofloxacin).

\section{Conclusions to date}

An unusual Salmonella serotype leading to a high rate of hospitalisation and the severe clinical picture of the cases detected in Finland and in the Czech Republic were important reasons for triggering the epidemiological investigation. According to data from the Finnish Infectious Disease Registry data base gathered between 2000 and 2009, less than $2 \%$ of all non-typhoidal salmonella findings were from blood. Similarly, in a large Spanish study, $4.5 \%$ of the patients with salmonellosis had septicaemia [1]. In the current cluster of S. Urbana, three cases of 14 had an invasive extraintestinal disease; two with bacteraemia and one with hematogeneous septic arthritis.

S. Urbana is rarely described in the literature. In the 1990s, a large outbreak occurred in a neonatal ward in Thailand [2] and a case of $S$. Urbana encephalopathy was reported from Japan [3]. The inquiry to the experts in the Programme on Food- and Waterborne Diseases and Zoonoses revealed that $S$. Urbana is rare in Europe in general, and mostly reported in children. Some of these cases had been associated with contacts with reptiles [4]. S. Urbana has also been found in sesame and equsi (melon) seeds, black pepper, animal feed and sewage sludge, according to experts in the Programme on Food- and Waterborne Diseases and Zoonoses network.

Only one of the cases (in the Czech Republic) had had contact with a reptile. According to our investigations, neither animals nor their feed seem to be the source of the current infections. Milk products appear to be less likely to be the source of infection, since one of the cases suffered from severe milk allergy. Fish, nuts, soya products and health food items were rarely consumed by the Finnish cases. Most of the cases were males, but we were not able to reveal any exposure common to the cases that could have been linked to being male.

Since the beginning of February, no further cases of $S$. Urbana have been detected in the three countries. Most of the cases had accumulated in two weeks in January in all three countries. The cases detected in the beginning of February were in a cancer patient without gastrointestinal symptoms (Salmonella found in blood) 
and an adult male who was considered a secondary case to his children that also suffered from gastrointestinal symptoms. When tested, however, the family members were negative for Salmonella. The accumulation of most cases with gastrointestinal symptoms in two weeks (Figure 2) suggests that the source of the infection could have been a product with a short shelflife such as a batch of fresh produce, or a minor contamination of some other product. To date however, the source of the outbreak remains unknown.

\section{Acknowledgements}

We thank the experts of the Programme on Food- and Waterborne Diseases and Zoonoses network for their kind response to our inquiry. The skilful assistance of the personnel of the National Salmonella Centre in Bacteriology Unit, National Institute for Health and Welfare is gratefully acknowledged for PFGE typing the strain from Latvia. Taina Niskanen and her team and Henry Kuronen and the laboratories of Finnish Food Safety Authority are thanked for organising and carrying out microbiological investigation and providing information on non-human $S$. Urbana isolates in Finland. Furthermore we are thankful to the local epidemiologists in the Czech Republic. Anita Brila and her team are acknowledged for the epidemiological investigation in Latvia. The PulseNet Europe curator Clare Maguire is thanked for providing international names for PFGE profiles.

\section{References}

1. Gil Prieto R, Alejandre CG, Meca AA, Barrera VH, de Miguel AG. Epidemiology of hospital-treated Salmonella infection; data from a national cohort over a ten-year period. J Infect. 2009;58(3):175-81.

2. Sirinavin S, Hotrakitya S, Suprasongsin C, Wannaying B, Pakeecheep S, Vorachit M. An outbreak of Salmonella urbana infection in neonatal nurseries. J Hosp Infect. 1991;18(3):231-8.

3. Minami K, Yanagawa T, Okuda M, Suzuki H, Tamura A, Izumi $\mathrm{G}$, et al. Cerebrospinal fluid cytokines in Salmonella urbana encephalopathy. Tohoku J Exp Med. 2004;203(2):129-32.

4. Kocianova H, Litvova S, Stefkovicova M, Gavacova D, Rovny I, Glosova L, et al. [Exotic Pets as a Potential Source of Salmonella]. Epidemiol Mikrobiol Immunol. 2010;59(1):9-12. [Czech].

5. European Centre for Disease Prevention and Control (ECDC). [Internet]. Programme on food and water-borne diseases and zoonoses. Available from: http://www.ecdc.europa.eu/EN/ ACTIVITIES/DISEASEPROGRAMMES/Pages/Programme on food_and_water-borne_diseases_and_zoonoses.aspx 